\title{
Biopolítica de Estados expulsores
}

\section{Biopolitics of Ejector States}

\author{
Héctor Claudio SILVEIRA GORSKI \\ Departamento de Derecho PúblicoUniversitat de Lleida \\ hsilveira@dpub.udl.cat
}

Recibido: 16.02 .2012

Aprobado definitivamente: 02.10 .2012

\section{RESUMEN}

La biopolítica sobre los migrantes se fundamenta en el binomio dejar entrar-residir o expulsar. Las leyes de extranjería están elaboradas sobre dos ejes: por un lado, en la regulación de los flujos migratorios en función del mercado de trabajo y las demandas de la economía y, por otro, en el control policial y la persecución de la inmigración irregular. Para la realización del primer eje del binomio, dejar entrar y residir, los Estados se dotan de mecanismos de regulación e intervención sobre el inmigrante concebido como fuerza de trabajo productiva. Asimismo los Estados crean mecanismos de control-sanción para las personas migrantes que incumplen los requisitos establecidos para entrar y residir en el territorio. En este punto la biopolítica sobre la población migrante se solapa o toma forma en el ejercicio de la soberanía por el Leviatán. Las medidas de control y sanción que los gobiernos ponen en marcha sobre los sin papeles han creado una imponente maquinaria de coacción en el interior de las instituciones del Estado de derecho hasta el punto de convertirlo en un Estado expulsor.

Palabras Clave: Biopolítica, migrantes, Estados expulsores, centros de internamiento, semipersonas, nopersonas.

\begin{abstract}
The biopolitics of migrants is based on the allow to enter-reside or expel binomial. Immigration laws are designed around two axes: first, the control of migration in terms of the labor market and the requirements of the economy and, secondly, the policing and prosecution of illegal immigration. To achieve the first axis of the binomial, namely allow to enter-reside, states deplloy mechanisms to control immigrants envisaged as a productive workforce. States also create control-punishment mechanisms for migrants who violate the requirements for entry and residence in the country. Here biopolitics on migration overlaps with, or takes shape through, the exercise of sovereignty by the Leviathan. The control measures and sanctions that governments apply to the undocumented have created an powerful machinery of coercion within the institutions of the rule of law to the point of converting it into an expelling state.
\end{abstract}

KeYwords: Biopolitic, migrants, Ejector states, Internment Centres for Foreigners, semi-persons, nonpersons.

\section{SUMARIO}

1.Dejar entrar-residir o expulsar. 2.Estados expulsores. 3.El migrante como semipersona en el subsistema jurídico de extranjería. 4. El migrante como desafío para el Estado de derecho y la democracia 
"habrá que preparar mecanismos reguladores que, en una población global, puedan determinar un equilibrio, conservar una media, establecer una especie de homeóstasis (...) mecanismos de seguridad en torno a todo lo que haya de aleatorio en las poblaciones de seres vivientes"

(Foucault, 1992: 255).

\section{DEJAR ENTRAR-RESIDIR O EXPULSAR}

El sistema legal-administrativo de extranjería es un ejemplo de lo que Foucault denomina "mecanismos globales" de regulación y de seguridad de la biopolítica (1992: 250). Por biopolítica nos referimos, siguiendo a Foucault, a todas aquellas decisiones y acciones de las instituciones políticas que afectan y determinan la vida de las personas de forma global. Desde la perspectiva de las instituciones de gobierno, la vida deja de ser un mero objeto para convertirse en el resultado de un conjunto de causas, fuerzas, intereses, acciones y reacciones en manos de las denominadas políticas de la vida (Esposito, 2004: 23). En los países europeos la biopolítica se encuentra hoy con la horma que le impone el Estado democrático de derecho, pero es una horma que, como veremos, no le impide poner en práctica políticas que directa o indirectamente causan exclusión, segregación y violencia en el seno de la población. Estas políticas, además, se realizan bajo formas sutiles de actuación, resguardadas en estructuras legales y en una supuesta legitimidad política. Uno de los ámbitos que se ve afectado por el biopoder es el de los flujos migratorios.

En las últimas décadas, los Estados de la Unión Europea han incorporado a sus políticas la regulación y gestión de los movimientos de millones de migrantes ${ }^{1}$ que buscan su incorporación al mercado de trabajo y que han transformado a las ciudades europeas en sociedades multiculturales. Nuevas leyes regulan hoy la entrada, permanencia y expulsión del territorio, el acceso al mercado de trabajo, los derechos y libertades y la inclusión en la comunidad de las personas migrantes.

La biopolítica sobre los migrantes se fundamenta en el binomio dejar entrar-residir o expulsar. Las leyes de extranjería están elaboradas sobre dos ejes: por un lado, en la regulación de los flujos migratorios en función del mercado de trabajo y las demandas de la economía y, por otro, en el control policial y la persecución de la inmigración irregular. El migrante que disponga de los permisos de residencia y trabajo correspondientes podrá entrar y residir en el territorio y si logra mantener su vinculación-adscripción al mercado laboral conseguirá renovarlos, para después, transcurridos unos años, iniciar los trámites para obtener la residencia permanente y en última instancia la nacionalidad. Mas, si no tiene los permisos, ya sea porque entró de forma irregular o bien porque no los renueva, se encontrará en la situación de "irregularidad" administrativa y con la amenaza permanente de la expulsión. La vida del inmigrante transcurre entre la integración en la comunidad receptora y la expulsión de ésta. Ello dependerá en gran parte de su incorporación al mercado de trabajo y de los controles de identificación que dos por tres realiza la policía. En torno a estos dos ejes el legislador español ha creado un subsistema institucional jurídico con instrumentos de regulación, gestión, control y sanción sobre los migrantes. La biopolítica sobre los migrantes hace uso de instrumentos de regulación-gestión conjuntamente con los de control-sanción. ${ }^{2}$

Para la realización del primer eje del binomio, dejar entrar y residir, los Estados se dotan de mecanismos de regulación e intervención sobre el inmigrante concebido como fuerza de trabajo productiva. No hay más que pasar revista a los títulos de los diversos reglamentos de extranjería ${ }^{3}$ elaborados por los distintos gobiernos españoles para ver que la mayoría están fundamentalmente dedicados a regular los regímenes de entrada, residencia y trabajo de los inmigrantes en función de la situación del mer-

${ }^{1}$ El número estimado de migrantes internacionales a nivel mundial es de 214 millones. En los últimos diez años los flujos han aumentado en 65 millones, de los 150 millones que había en el año 2000 (Fuente OIM, Hechos y cifras).

${ }^{2}$ Para un análisis de estos conceptos en la obra de Foucault ver Campesi (2011: 141).

${ }^{3}$ Real Decreto 155/1996, de 2 de febrero; el RD 864/2001, de 20 de julio; RD 2392/2004, de 30 de diciembre. 
cado laboral. ${ }^{4}$ Once de los quince títulos del último reglamento regulan la entrada, el tránsito aeroportuario, la estancia, la residencia temporal y de larga duración, las autorizaciones de residencia y trabajo, las contrataciones en origen y los trabajadores fronterizos. Las políticas públicas que se ocupen de los flujos migratorios deben ordenarse, establece el legislador español en la última reforma de la ley de extranjería, "de acuerdo con las necesidades de la situación nacional de empleo" (art.2 bis2 LOEx $^{5}$ ).

Ordenada la entrada y la residencia en el territorio los poderes públicos deben promover "la plena integración de los extranjeros en la sociedad española en un marco de convivencia de identidades y culturas diversas sin más límite que el respeto a la Constitución y a la ley" (art.2ter.1 LOEx). Estas políticas deberían ser incorporadas, continúa el legislador, con carácter transversal a todas las políticas y servicios público, junto con la promoción de "la participación económica, social, cultural y política de las personas inmigrantes, en los términos previstos en la Constitución, en los Estatutos de Autonomía y en las demás leyes, en condiciones de igualdad de trato" (art.2ter.2 LOEx)

Por su parte y para alcanzar estos objetivos el gobierno impulsa la realización de planes estratégicos de ciudadanía e integración. Estos están regidos en los principios de: a) igualdad y no discriminación, en el sentido de la equiparación de derechos y obligaciones de la población inmigrada y autóctona, dentro del marco de los valores constitucionales básicos; b) ciudadanía, con el objetivo de buscar el reconocimiento de la plena participación cívica, social, económica, cultural y política de los ciudadanos y ciudadanas inmigrantes; c) interculturalidad, como mecanismo de interacción entre las personas de distintos orígenes y culturas, dentro de la valora- ción y el respeto de la diversidad cultural" (PECI, 2007:30), y d) inclusión, consistente en la creación de procesos que permitan superar las desventajas sociales, económicas, personales y culturales que permitan que se esté en condiciones de gozar de los derechos sociales y ejercer la participación ciudadana superando el estatus de persona asistida y la estigmatización que conlleva la pobreza, la marginación y la exclusión (II PECI, 2011:79). En el marco de la reorganización del nuevo sistema de producción los Estados deben dotarse de mecanismos de gobierno de carácter integral con el fin de conseguir principalmente la inclusión del migrante en el sistema de producción y, de paso, en la forma de vida de la sociedad receptora.

Junto a estas políticas de promoción de la igualdad y de la inclusión los Estados deben dotarse también de mecanismos de control-sanción de aquellos migrantes que incumplen los requisitos establecidos para entrar y residir en el territorio. En este punto la biopolítica sobre la población migrante se solapa o toma forma en el ejercicio de la soberanía por el Leviatán. Este, paradójicamente, utiliza su poder coactivo para reafirmar la soberanía sobre sus fronteras y su territorio a la vez que la va perdiendo en el marco de la globalización. En este sentido, podemos decir que la biopolítica sobre los migrantes se desarrolla en la geografía y en los nuevos espacios de soberanía que está diseñando el proceso de la globalización.

\section{ESTADOS EXPULSORES}

Las medidas de control y sanción que los gobiernos europeos han puesto en marcha sobre los migrantes han creado una imponente maquinaria de coacción en el interior de las instituciones del Es-

${ }^{4}$ Sobre el funcionamiento del mercado laboral y sus consecuencias para el migrante ver por todos Achón (2011).

${ }^{5}$ Ley Orgánica 4/2000, de 11 de enero, sobre derechos y libertades de los extranjeros en España y su integración social, reformada por la LO 8/2000, de 22 de diciembre, la LO 11/2003, de 29 de septiembre, la LO 14/2003, de 20 de noviembre, y la LO 2/2009, de 11 de diciembre.

${ }^{6}$ Las administraciones con competencias en esta materia deben regir sus actuaciones sobre principios como el de. a) igualdad efectiva entre hombres y mujeres; b) efectividad del principio de no discriminación y, consecuentemente, el reconocimiento de iguales derechos y obligaciones para todos aquellos que vivan o trabajen legalmente en España, en los términos previstos en la ley; c) garantía del ejercicio de los derechos que la Constitución, los tratados internacionales y las leyes reconocen a todas las personas; d) lucha contra el inmigración irregular y la persecución del tráfico ilícito de personas (art.2bis2 LOEx). 
tado de derecho. La biopolítica de las expulsiones convierte a los Estados en Estados expulsores. Estos llevan a cabo medidas de expulsión y devolución de personas extranjeras de su territorio o las rechazan en sus fronteras a través de procedimientos administrativos que suelen ir acompañados de la retención e internamiento de personas migrantes en cárceles administrativas creadas especialmente para estos casos.

La aprobación de la Directiva de retorno ${ }^{7}$ de inmigrantes por el Parlamento y el Consejo de la Unión Europea consolidó las políticas y medidas policiales de los Estados "expulsores", marcando, a su vez, un importante retroceso de los Estados de derecho europeos. Con la Directiva se abre la puerta, por ejemplo, a que los migrantes sean privados de libertad -internados- por una simple orden administrativa (art.15.2) por un período de 6 meses prorrogables hasta 12 meses (arts.15.5 y 15.6); que el inmigrante no reciba asistencia jurídica y/o representación legal si no lo solicita previamente (art.13.4), el internamiento y la expulsión de menores extranjeros no acompañados y familias con menores (arts.10 y 17), $y$ en el caso de que el inmigrante no pueda ser expulsado, a que permanezca en el territorio europeo bajo una situación legal incierta, incluso como "alegal". En relación a los extranjeros que no pueden ser expulsados la Directiva determina que los Estados deberán abordar su situación y "definir sus condiciones básicas de subsistencia según la legislación nacional" (considerando 12), lo que de por sí sólo no determina que aquél surja de la situación de precariedad legal y social en la que de hecho se encuentra.

Las medidas administrativas de expulsión y devolución, junto con los procedimientos de retorno, ${ }^{8}$ integran la denominada política de repatriación de los gobiernos europeos. Año tras año miles de inmigrantes extracomunitarios son rechazados en las fronteras o son detenidos y expulsados del territorio europeo. En el año 2009, el conjunto de los países de la Unión Europea detuvieron (apprehend) ${ }^{9}$ a unos 570.000 migrantes irregulares, de los cuales unos 228.000 (un 40\%) fueron expulsados a sus países de origen. ${ }^{10}$ Los datos sobre personas migrantes detenidas, internadas y expulsadas en cuatro países del sur del Mediterráneo -España, Grecia, Italia y Portugal-, antes países de emigrantes y hoy receptores de importantes flujos migratorios, son reveladores de la dimensión que han adquirido estas políticas en los Estados expulsores.

\subsection{Personas migrantes detenidas, interna- das y expulsadas}

Del análisis global de los datos de estos cuatro países mediterráneos se desprende en primer lugar el alto número de inmigrantes que son detenidos, internados y expulsados. En total, entre los cuatro países, y en el período que va del año 2000 al 2009, se detuvieron alrededor de 2.258 .128 , se privaron de libertad en centros de internamiento a 454.639 y se expulsaron alrededor de 697.784 migrantes. Entre el año 2000 y el 2007, España detuvo a 439.002 personas extranjeras, con una media de detenciones por año de 54.875; Grecia a 1.053.540, con una media por año de 117.060 (años 2000-2008), Italia a 624.976, y una media por año de 78.122 y Portugal a 140.624 , con una media por año de $17.578 .{ }^{11} \mathrm{Si}$ nos fijamos en las personas privadas de libertad en CIE, en España, entre los años 2000 y 2004, fueron

${ }^{7}$ Directiva 2008/115/CE del Parlamento Europeo y del Consejo, de 16 de diciembre, publicada en el Diario Oficial de la Unión Europea del 24/12/2008. Fue aprobada por el Parlamento el 18/06/08 y por el Consejo el 09/12/08. Sobre esta Directiva, llamada también de la infamia o de la vergüenza, y sus efectos sobre los derechos humanos ver AgüeloChueca (2008); Pavón (2008), De Lucas (2008), Chueca (2010).

${ }^{8}$ El procedimiento administrativo de retorno se aplica a las entradas no autorizadas, no a las ilegales. El retorno se aplica cuando en la frontera no se permite al extranjero entrar por no reunir los requisitos establecidos para la entrada en el territorio (Art. 26.2 LOEx).

${ }^{9}$ Aprehend: suma de los extranjeros indocumentados detenidos en el territorio y de extranjeros itentando entrar de forma irregular por puestos no fronterizos. Sobre los controles de identidad y detenciones de inmigrantes "sin papeles" ver Martínez Escamilla-Sánchez Tomás (2011).

${ }^{10}$ Para sufragar estas expulsiones la Unión Europea dispone de un fondo con 676 millones de euros para el período 2008-2013. Fuente: European Commission. Home Affairs.

${ }^{11}$ Para un análisis más a fondo de estos datos ver Silveira (2011: 237-258). 
privadas de libertad 38.901 personas extranjeras; en Grecia 303.456 entre el año 2000 y el 2008; y en Italia 65.859 entre el año 2003 y el 2008. De Portugal no hay datos oficiales sobre extranjeros internados en centros de internamiento (ver tabla 2 en Silveira, 2011: 241-243). En cuanto a las expulsiones, en España, desde el año 2000 hasta el año 2009, fueron expulsadas y devueltas ${ }^{12} 258.149$ personas extranjeras, en Grecia 156.209 (2000-2008, en Italia 265.015 (2000-2008) y en Portugal 18.231 (2000-2007). En España la media de expulsiones y devoluciones por año en el período 2000-2009 fue de 25.814 personas extranjeras, en Grecia de 17.376 en el período 2000-2008, en Italia de 29.446 y en Portugal de 2.279 personas extranjeras expulsadas del territorio (ver tabla 3 en Silveira, 2011: 244-246).

En este marco hay que denunciar la privación de libertad, las expulsiones y repatriaciones de menores extranjeros no acompañados que vienen realizando los gobiernos europeos en los últimos años. Al respecto, España repatrió a 582 menores en el año 2004, a 412 en el 2005, a 1657 en el 2006, a 1380 en el 2007 y a 379 en el 2008 (EMN 2009a). Uno de los problemas más graves que afrontan estos menores son las pruebas que les realizan la administración para calcular su edad. Estas pruebas son importantes porque la mayoría de edad es lo que determina que puedan ser expulsados o bien, si son menores, tengan que ser repatriados previa existencia de un convenio bilateral. En España, como denuncia el Defensor del Pueblo (2011), el sistema establecido para determinar la edad no funciona de forma correcta, las pruebas presentan escaso fundamento científico, son poco fiables, arbitrarias y conculcan derechos fundamentales como el de no dar asistencia jurídica gratuita al menor.

\section{EL MIGRANTE COMO SEMIPERSONA EN EL SUBSISTEMA JURÍDICO DE EXTRANJERÍA}

Después de más de tres décadas de vigencia, las legislaciones de extranjería configuran importantes subsistemas jurídicos en los Estados europeos. En España, la última reforma de la ley de extranjería (en adelante LOEx) del año 2009 introdujo cambios relevantes en el conjunto del redactado, especialmente en el catálogo de derechos y libertades. Como principales novedades se reconoce el derecho a la educación a los extranjeros menores de dieciocho años (art. 9) y los derechos a la asistencia jurídica gratuita (art.22), de reunión (art.7), asociación (art.8), sindicación y huelga (art.11) a todos los extranjeros. El legislador optó por no entrar en la discusión que se había abierto sobre la regulación de estos últimos cuatro derechos estableciendo ahora, sin cortapisas, que todo extranjero, cualquiera que sea su situación administrativa, tiene derecho a ejercitarlos en las mismas condiciones que los españoles.

Estos derechos han pasado a integrar el subsistema legal-administrativo que el legislador ha creado para gestionar los flujos migratorios y regular la residencia y el trabajo de las personas migrantes en el territorio. La LOEx reconoce al extranjero que se encuentre en España, independientemente de cuál sea su situación administrativa, regular o irregular, los derechos: a la documentación (art.4); a la tutela judicial efectiva (art.20); al recurso contra los actos administrativos (art.21); a la asistencia sanitaria pública de urgencia ante la contracción de enfermedades graves o accidentes (art.12.2); a la asistencia sanitaria en las mismas condiciones que los españoles para los menores de dieciocho años (art.12.3), las extranjeras embarazadas tienen derecho a la asistencia sanitaria durante el embarazo, parto y postparto (art.12.4), a sindicarse libremente y a ejercer el derecho de huelga (art.11), derecho de reunión y manifestación (art.7) y derecho a asociación (art.8); a

\footnotetext{
${ }^{12}$ Devoluciones: son devueltas las personas migrantes que tratan de entrar en España por puestos no habilitados como fronteras. En España la expulsión (art. 57 LOEx) y la devolución (art. 58 LOEx) son dos procedimientos administrativos distintos. La expulsión se aplica a los extranjeros que realicen conductas tipificadas como muy graves, o conductas graves de las previstas en los apartados a), b), c), d) yf) del artículo 53.1 de la Ley Orgánica de Extranjería (art. 57 LOEx). La devolución, en cambio, se aplica a los extranjeros que hayan sido expulsados y contravengan la prohibición de entrada y a aquellos que pretendan entrar ilegalmente en el país y sean interceptados en la frontera o en sus inmediaciones. La devolución no requiere la tramitación del expediente de expulsión (art. 58 LOEx)
} 
transferir sus ingresos y ahorros obtenidos en España a su país o a cualquier otro (art.15.2) y el derecho a la asistencia sanitaria, en las mismas condiciones que los españoles, si están inscritos en el padrón del municipio en el que tengan su domicilio habitual (art.12.1).

Los extranjeros residentes tienen, además, los derechos a: la participación pública en las elecciones municipales, en los términos establecidos en la $\mathrm{CE}$, en los tratados y en la ley (art.6) ${ }^{13}$; al trabajo y a la Seguridad Social, si cumplen con los requisitos previstos en la LOEx (art.10); en materia de vivienda (art.13); a las prestaciones y servicios de la Seguridad Social en las mismas condiciones que los españoles (art.14); a la vida en familia y a la intimidad familiar (art.16.1) y a reagrupar con ellos a los familiares que se determinan en el art.17 de la LOEx (art.16.2). En cambio, los derechos a la libertad de circulación y a elegir residencia quedan relegados a aquellos extranjeros que se hallen en España cumpliendo los requisitos para entrar en el territorio y tengan la documentación en regla, sin más limitaciones que las establecidas con carácter general por los tratados y las leyes o la autoridad judicial (art.5).

Junto a estos derechos, libertades y garantías la persona migrante se encuentra con otras disposiciones normativas que regulan medidas de control y sanción y que la discriminan o excluyen de la comunidad en la que habita. Estas leyes, con sus correspondientes prácticas administrativas, constituyen un subsistema jurídico en el que el migrante es tratado como una "semipersona" o incluso como una nopersona en los procedimientos de internamiento y expulsión del territorio. ${ }^{14}$ La condición de extranjero sigue actuando como una barrera infranqueable en los Estados-nación al reconocimiento del migrante como un sujeto con plenos derechos y que no puede ser discriminado por su origen étnico o su procedencia en cumplimiento del principio de igualdad.

\subsection{La triada de derechos y libertades de las personas migrantes}

El punto de partida de la conversión del migrante en una semipersona está en la Constitución española. Esta establece que los extranjeros gozan en España de los derechos y libertades reconocidos en su Título I, al igual que los españoles, teniendo en cuenta los términos de las regulaciones establecidos en los Tratados Internacionales, en la propia LOEx y en las leyes que regulen el ejercicio de cada uno de ellos (art. 13). A partir de aquí y desde la sentencia del Tribunal Constitucional (STC) 107/1984 la doctrina jurídica y la jurisprudencia distinguen entre derechos y libertades que corresponden por igual a españoles y extranjeros, otros que pueden ser diferentes entre españoles y extranjeros y otros que sólo pertenecen a los ciudadanos españoles.

En primer lugar, están los derechos fundamentales cuya regulación legal no puede tener en cuenta la nacionalidad del titular. Estos derechos pertenecen a la persona en cuanto tal, "corresponden por igual a españoles y extranjeros" y su regulación ha de ser igual para ambos (STC 107/1984, F.J.3º). Desde un punto de vista constitucional son considerados inviolables por ser "imprescindibles para la garantía de la dignidad humana". Configuran un estándar mínimo regulado en tratados y convenios internacionales que el legislador debe respetar a la hora de legislar sobre ellos. Forman parte de este grupo de derechos de las personas el derecho a la vida y a la integridad física y moral (art. $15 \mathrm{CE}$ ); a la libertad religiosa y de culto de los individuos y las comunidades (art. $16 \mathrm{CE}$ ); a la libertad y a la seguridad (art. $17 \mathrm{CE}$ ); al honor, a la intimidad personal y familiar (art. $18 \mathrm{CE}$ ), a la tutela judicial efectiva (24 CE) y a no ser discriminado por razón de nacimiento, raza, sexo, religión o cualquier otra condición o circunstancia personal o social (art. $14 \mathrm{CE}$ ).

Junto a los derechos de la persona hay un segundo ámbito donde estarían los derechos fundamentales de los extranjeros cuyo contenido puede ser

\footnotetext{
${ }^{13}$ Los extranjeros residentes en España podrán ser titulares del derecho de sufragio, en las elecciones municipales, en los términos establecidos en las leyes (art.6.1 LOEx). Los residentes empadronados en un municipio tienen también reconocidos los derechos establecidos por tal concepto en la legislación de bases de régimen local, pudiendo ser oídos en los asuntos que les afecten de acuerdo con lo que disponga la normativa específica (art.6.2 LOEx).

${ }^{14}$ Sobre los conceptos de semipersona y no-persona me permito reenviar a Silveira (2010).
} 
objeto de regulación por las leyes y los tratados. En este grupo estarían los derechos al trabajo (art. 35 $\mathrm{CE}$ ), a la Seguridad Social y a percibir una prestación por desempleo (art. $41 \mathrm{CE}$ ), a la protección de la salud (art. 43) y el derecho de residencia y circulación en España (art. 19 CE). Estos derechos, a diferencia de los del primer ámbito no son considerados inherentes a la dignidad de la persona, mas el legislador no puede excluir a los extranjeros de estos derechos, debe respetar las prescripciones constitucionales, pero puede establecer "condicionamientos adicionales respecto a su ejercicio por parte de aquéllos" (STC 236/2007, F.J.4 $4^{\circ}$ ). Las leyes y los tratados podrán "modular" o "atemperar" el ejercicio de estos derechos por parte de los extranjeros pero sin llegar a establecer diferencias injustificables con los españoles. La jurisprudencia constitucional considera que las condiciones que establezca el legislador para el ejercicio de los derechos y libertades por parte de los extranjeros sólo serán válidas si respetan el contenido esencial de aquéllos y "se dirigen a preservar otros derechos, bienes o intereses constitucionalmente protegidos y guardan adecuada proporcionalidad con la finalidad protegida" (STC 236/2007, F.J. $4^{\circ}$ ). Por ello, entendemos que es ilegal el Decreto 1192/2012, de 3 de agosto, en el que el gobierno español, hoy en manos del Partido Popular, deja sin atención atención médico-sanitaria a los extranjeros en situación irregular. El derecho a la salud es un derecho que tiene toda persona y del que nadie puede ser excluido. Es un derecho humano de carácter universal, indivisible e inalienable y así está reconocido en la constitución española, en numerosos tratados internacionales y en la Carta de Derechos Fundamentales de la Unión Europea (art. 35). La exclusión legal de los extranjeros en situación irregular -sin papeles- del acceso a este derecho quiebra la legalidad y abre una profunda brecha en la sociedad española entre personas que ven reconocidos todos sus derechos y otros que los ven rebajados o se ven excluidos de ellos y que suelen ser los que menos recursos tienen. Supone otra discriminación de la persona migrante y pone en cuestión la democracia y la vida en común en una sociedad que en los últimos años ha devenido multicultural.

En tercer lugar, estaría el ámbito de los derechos fundamentales que sólo pertenecerían a los españoles. Los extranjeros no tendrían acceso a estos derechos porque son considerados por el ordenamiento y la doctrina jurídicas inherentes a la condición de ciudadano. En este ámbito estarían los derechos vinculados al artículo 23 de la Constitución española, como los derechos de participación en los asuntos públicos, y de acceso a funciones y cargos públicos. Esta exclusión, sin embargo, da lugar a una de las discriminaciones más importantes que sufren los migrantes residentes: la de no poder participar en los procesos de elección de los representantes políticos que legislan y gobiernan sobre los asuntos generales de la comunidad en la que habitan. El inmigrante extranjero es tratado como un meteco, en el sentido de que el legislador le concede derechos civiles, sociales y libertades fundamentales, pero no le reconoce los derechos políticos, excepto en el ámbito municipal. La contaminación del principio de ciudadanía por el principio de la nacionalidad continúa manteniendo lo que en su día Balibar calificó como un "apartheid" en contradicción flagrante con un modelo democrático de sociedad (2003: 87).

Para hacer algo más pequeño este apartheid el gobierno español ha venido firmando acuerdos de reciprocidad sobre la participación en las elecciones municipales con varios países de origen de los más de 5,5 millones de extranjeros radicados en su territorio. A inicios de 2011 había 5.730.667 extranjeros inscritos en el Padrón Municipal de Habitantes, el $12,2 \%$ de una población total de 47.150 .819 habitantes. Los extranjeros residentes pertenecientes a los 27 países de la Unión Europea suman 2.392.491 ${ }^{15}$ y los no comunitarios 3.338.176. ${ }^{16}$ En las últimas elecciones locales del 22 de mayo de 2011 tenían la posibilidad de votar ciudadanos residentes de la Unión Europea y extranjeros extracomunitarios de países con acuerdos de reciprocidad en vigor suscritos con España e inscritos en el censo electoral. Antes de esa fecha el gobierno español había alcanzado a firmar

${ }^{15}$ Los extranjeros pertenecientes a la UE representan el 41,7\% del total -los rumanos son los más numerosos (864.278), seguidos por los británicos (390.880) y los alemanes (195.842)- seguidos de los procedentes de América Latina, con un $24,8 \%$. Fuente OPI.

${ }^{16}$ Entre estos destacan 769.920 marroquíes, 359.076 ecuatorianos y 271.773 colombianos. 
convenios con Bolivia, Chile, Colombia, Ecuador, Paraguay, Perú, Noruega, Nueva Zelanda, Islandia y Cabo Verde. ${ }^{17}$ Ello llevó a que el total de los extranjeros residentes con derecho a voto por su nacionalidad alcanzara la cifra de 2,5 millones, de los cuales se registraron en el censo electoral alrededor de 475.000. De estos, a pesar de todo, muy pocos llegaron a ejercitar realmente su voto. ${ }^{18}$

\subsection{Derechos y libertades según el "grado de conexión" con la dignidad}

El Tribunal Constitucional volvió a revisar los derechos y libertades de los extranjeros en la sentencia 236/2007 partiendo de la base de que "todos los derechos fundamentales, por su misma naturaleza, están vinculados a la dignidad humana" (FJ3). Los magistrados del tribunal tenían que dilucidar hasta qué punto la vinculación existente entre los derechos y la dignidad era determinante para considerar que un derecho es "inherente" a la dignidad y, en consecuencia, debe tener la misma regulación para todas las personas, inmigrantes incluidos.

Para solventar esta dificultad y determinar en el futuro la configuración legal del derecho el tribunal elaboró un nuevo instrumento de medición de los derechos: la existencia de un "grado de conexión" entre el derecho fundamental y la dignidad humana. Este grado es lo que le permitirá valorar la constitucionalidad de las disposiciones normativas que afecten a los derechos fundamentales de los extranjeros. El grado de conexión es lo que determinaría hasta dónde llega la libertad que tiene el legislador para regular los derechos fundamentales. En relación a aquellos que la doctrina considera "imprescindibles para la garantía de la dignidad humana" el legislador no puede modular o atemperar su contenido (STC 99/1985, $\mathrm{FJ}^{\circ}$ ) ni por supuesto negar su ejercicio a los extranjeros, cualquiera que sea su situación, ya que se trata de derechos "que pertenecen a la persona en cuanto tal y no como ciudadano" (STC 236/2007, $\mathrm{FJ}^{\circ}{ }^{\circ}$. Con esta nueva doctrina sobre el grado de conexión entre el derecho fundamental y la dignidad de la persona la triple división de la STC 107/1984 queda reducida, en realidad, a dos: los derechos fundamentales de los ciudadanos (de los españoles) y los otros derechos fundamentales "que por su mayor o menor vinculación con la dignidad de la persona, pertenecerían a los extranjeros y a los nacionales aunque el legislador puede imponer a los extranjeros ciertos condicionamientos adicionales para el ejercicio de éstos, siempre que se respete su contenido esencial" (Pómez-Ortega-Ripoll 2010, 74).

\subsection{La creación de un subsistema de coac- ción específico para inmigrantes}

La conversión de los Estados europeos en máquinas de expulsión de extranjeros ha llevado a los gobiernos y a la administración a crear un subsistema jurídico sancionador, con reglas específicas para detener, internar y expulsar extranjeros. Al amparo de este subsistema ha nacido una cultura administrativo-penal que configura a la inmigración irregular como un "cuasi-delito" y que no duda en utilizar el internamiento y las expulsiones como un instrumento de control social.

Las leyes sobre infracciones y sanciones en materia de extranjería forman un subsistema de coacción específico sobre el migrante dentro del sistema jurídico de extranjería. Este subsistema está formado por un conjunto de infracciones leves, graves y muy graves, cada una con sus correspondientes sanciones, consistentes básicamente en la imposición de multas, desde los 500 hasta los 100.000

\footnotetext{
${ }^{17}$ Estos Estados, tal y como exige la Constitución Española (art. 13) reconocen el derecho de voto en las elecciones municipales a los ciudadanos españoles residentes en su territorio. Los inmigrantes pertenecientes a los países con acuerdos de reciprocidad sumaban un total de 350.287 posibles votantes para las elecciones municipales de mayo de 2011. El país con más votantes potenciales era Ecuador, con 168.639 (de un total de 359.076 ecuatorianos), seguido de Colombia, con 95.192 (de un total de 271.773 colombianos), Perú con 38.244, Bolivia con 27.502, Chile con 10.078, Noruega con 6.027, Paraguay con 4.305, Islandia con 152 y Nueva Zelanda con 148. Hasta entonces sólo habían podido votar los ciudadanos noruegos.

${ }^{18}$ Estudios realizados sobre el colectivo de extranjeros europeos radicados en territorio español señalan que la tasa de abstención del voto extranjero en las elecciones municipales es muy alta, llegando incluso a alcanzar el $95 \%$ en municipios con mayorías significativas de extranjeros residentes (OEG, 2011:4).
} 
euros, y en la expulsión del territorio, junto con un conjunto de medidas cautelares, entre las que está el internamiento en un Centro de Internamiento de Extranjeros (en adelante CIE). Con estas normas el legislador busca dar instrumentos de intervención a las fuerzas de seguridad para controlar a la inmigración irregular y facilitar el retorno y las medidas de expulsión hacia los países de origen.

\section{a) Normas para expulsar}

Algunos ejemplos de este tipo de normas son, por ejemplo, el artículo 53.f de la ley de extranjería (LOEx), norma en blanco que abre la puerta a que la policía pueda iniciar procedimientos de expulsión sobre la consideración de múltiples actos, poco definidos por la ley, y que cataloga como contrarios al orden público; o bien el artículo 57.2 LOEx, que permite que la policía expulse al extranjero si éste ha sido condenado, dentro o fuera de España, por una conducta dolosa que constituya en España un delito sancionado con pena privativa de libertad superior a un año, previa tramitación del correspondiente expediente.

El legislador regula también que la expulsión se produzca en el proceso y/o la ejecución penal. El juez podrá autorizar la expulsión si el extranjero está procesado o imputado en un procedimiento judicial por delito o falta para el que la Ley prevea una pena privativa de libertad inferior a seis años, y conste este hecho acreditado en el procedimiento de expulsión (art.57.7 LOEx). En estos casos la expulsión se produce como consecuencia de que el juez decide que se ejecute la medida administrativa de expulsión sin que se realice el proceso y haya un pronunciamiento judicial específico sobre el delito o falta que haya realizado. Asimismo, el legislador obliga a que el juez substituya por la expulsión las penas privativas de libertad inferiores a seis años o las medidas de seguridad impuestas al extranjero sin residencia legal en España, salvo que considere que debe cumplir la condena en territorio español (arts.89 y 108 Código Penal). También está obligado a hacerlo en el caso de que el extranjero hubiera de cumplir o estuviera cumpliendo cualquier pena privativa de libertad y hubiera accedido al tercer grado penitenciario o cumplido las tres cuartas partes de la condena (art.89.5 CP). Las sanciones administrativas sobre los migrantes, no sólo han crecido de forma exponencial en los últimos años, sino que han entrado a contaminar de forma importante también el sistema penal.

En relación con estas expulsiones judiciales, la Dirección General de Servicios Penitenciarios de la Generalitat de Catalunya quiere fomentar las expulsiones de los presos extranjeros "sin papeles" que hayan cumplido la mitad de la condena o que no tengan prevista la substitución de la pena o una parte de ella por la expulsión. Para ello ha dado instrucciones de restringir el acceso de estos presos al régimen abierto y a las salidas programadas, proponiendo abiertamente su clasificación en el segundo grado. ${ }^{19}$ Con esta medida la Generalitat de Catalunya bloquea el posible proceso de reinserción social de estas personas, contemplado en el art. 25.2 CE, y abre la puerta a un trato, en consecuencia, discriminatorio del preso extranjero. Con esta medida de mantenimiento del extranjero en las cárceles la Generalitat busca también facilitar que la Delegación del Gobierno lleve adelante las expulsiones contempladas en el Código Penal. Con ello se lograría también rebajar el altísimo número de personas presas en las cárceles catalanas, como consecuencia de la aplicación de uno de los códigos penales más punitivos de Europa occidental. La ejecución de estas medidas puede llegar a tener un amplio impacto carcelario ya que casi la mitad de los internos - un $45 \%$ de las cárceles catalanas son extranjeros, de los que alrededor de 2000 no tienen permiso de residencia y trabajo. ${ }^{20}$

${ }^{19}$ En la Circular 1/2011 sobre estrangeria als centres penitenciaris de Catalunya la Dirección General de Servicios Penitenciarios recomienda claramente que las personas internas extranjeras que tengan una resolución y/o administrativa de expulsión del territorio nacional pasen a ser clasificadas en segundo grado. También deberán ser clasificadas en segundo grado aquellas en que en su sentencia condenatoria no se prevea la substitución de la pena por la expulsión pero no tengan vínculos socio familiares en el territorio y no tengan documentación regularizada (2011: 34-35).

${ }^{20}$ A finales del año 2010 había 10.520 personas (744 mujeres) presas en las cárceles catalanas. Fuente Departament de Justícia de la Generalitat de Catalunya 
Además de la distintas situaciones en las que el inmigrante se puede encontrar inmerso en un procedimiento de expulsión tendrá que hacer frente también a serias dificultades para ejercitar su derecho a la tutela y a la defensa judicial efectiva en aquéllos. La ley, por ejemplo, faculta a la policía a hacer uso de un procedimiento preferente de expulsión, ante el cual el inmigrante tiene sólo 48 horas para presentar alegaciones. Otro ejemplo que abunda en la idea de que lo que busca el legislador es facilitar la ejecución de este tipo de medidas es la conversión automática que el establece el legislador de la propuesta de expulsión en decreto de expulsión, si el inmigrante no presenta alegaciones a la primera (art.63.1,2 LOEx). Esta rebaja en las garantías procesales sitúa al inmigrante en una situación de mayor indefensión que la que tienen los españoles ante la propia administración, lo que evidencia, una vez más, un trato desigual e incluso discriminatorio de los extranjeros respecto a los españoles. A la hora de defenderse ante la administración el extranjero tiene menos garantías que el ciudadano español (arts.35,79 y 80 de la Ley 30/1992).

Otra de las dificultades añadidas con las que se encuentra el migrante es el papel que juegan las fuerzas de seguridad a la hora de interpretar y aplicar las normas sancionadoras. Al respecto, uno de los caballos de batalla de los últimos años de las asociaciones de inmigrantes y de organizaciones defensoras de los derechos humanos ha sido el cuestionar la práctica habitual de la policía de sancionar con la expulsión la estancia irregular cuando la ley establece que en primer lugar la sanción tiene que ser la de la multa (art. 7.1 LOEx). En lugar de multa la policía aplica ilegalmente directamente la sanción de expulsión. Este afán expulsor de las fuerzas de seguridad del Estado, que sólo puede responder a criterios políticos adoptados por el gobierno de turno, ha intentado ser corregido en los últimos años por los jueces. En concreto, el Tribunal Supremo ha casado varias resoluciones judiciales reafirmando la interpretación de que la sanción principal en casos de estancia irregular debe ser en primer lugar la multa y que, además, en el caso de la policía opte por aplicar la expulsión debe motivar esta medida de forma expresa. ${ }^{21}$

\section{b) Normas para vigilar y controlar}

La legislación de extranjería prevé también medidas específicas de control y vigilancia sobre las personas migrantes. Organismos públicos como la Agencia Estatal de Administración Tributaria, la Tesorería General de la Seguridad Social y el Instituto Nacional de Estadística deben facilitar a los órganos de la Administración General del Estado competentes en los procedimientos regulados en la LOEx "el acceso directo a los ficheros en los que obren datos que hayan de constar en dichos expedientes, y sin que sea preciso el consentimiento de los interesados" (Disp. Ad.Quinta LOEx). Asimismo la Dirección General de la Policía podrá acceder también a los datos de inscripción padronal de los extranjeros existentes en los Padrones Municipales para la exclusiva finalidad del ejercicio de las competencias establecidas en la ley de extranjería sobre control y permanencia de extranjeros en España (Disp. Ad. Séptima de la Ley 7/1985, de 2 de abril, Reguladora de las Bases del Régimen Local). Esta habilitación, sin embargo, contradice el artículo 22.2 de la Ley 15/99, de 13 de diciembre de Protección de Datos de carácter personal, que establece que la policía puede acceder a los datos personales pero sólo con el fin claro y determinado de prevenir "un peligro real para la seguridad pública y para la represión de las infracciones penales" (art. 22). El acceso a los datos de los extranjeros se convierte, por decisión del legislador, en algo general y ordinario, cuando, en cambio, el acceso a los datos de españoles se permite sólo de forma excepcional y por causa justificada. Las medidas de control y vigilancia se extienden

${ }^{21}$ Ver Recurso 9787/2003 y 10273/2003 de 18 de enero de 2007, recurso 8735/2003, de 25 de enero de 2007, recurso n. 7986/2003, de 9 de marzo de 2007. Las numerosas sentencias de este tribunal casando aplicaciones de la ley inválidas ha obligado a la Dirección General de Policía ha elaborar una nueva Circular (8/07) con instrucciones para la elaboración de expedientes sancionadores por estancia irregular. En ella se hace explícito que en los casos en que sólo exista "permanencia ilegal" los funcionarios deberán proceder a formular propuestas de sanción de multa, aplazando, en estos casos, la expulsión para cuando se produzca una segunda detención, como sanción por no cumplir la orden administrativa de abandono del territorio formulada en el primer expediente. 
también a los transportistas de viajeros. Estos, según el artículo 66 de la LOEx y en cumplimiento de las Directivas $2001 / 51 / \mathrm{CE}^{22}$ y $2004 / 82 / \mathrm{CE}^{23}$, tienen que facilitar a las autoridades españolas información relativa a los pasajeros que vayan a ser trasladados al territorio español, comprobar la validez y vigencia de sus documentos y en caso de denegaciones de entrada por deficiencias en la documentación necesaria para el cruce de fronteras hacerse cargo de los extranjeros. Ya no es una institución pública la que realiza las labores de control sino empresas privadas.

c) normas y prácticas policiales que discriminan $y$ atemorizan

Los controles de identificación por el perfil étnico y racial que realiza habitualmente la policía sobre los migrantes en vías y espacios públicos son otro ejemplo de las discriminaciones que sufren éstas personas en territorio español. Así lo vienen denunciando asociaciones protectoras de los derechos humanos e instituciones internacionales que velan por su cumplimiento. En uno los últimos informes de Amnistía Internacional sobre España se dice que "a pesar de la amplia variedad de instrumentos jurídicos que prohíben claramente la discriminación por motivos tales como la raza, las investigaciones de Amnistía Internacional y otras organizaciones revelan que la práctica de aplicar perfiles raciales está muy extendida en España entre los funcionarios encargados de hacer cumplir la ley" (2011:5). Asimismo, el Comité de las Naciones Unidas para la Eliminación de la Discriminación Racial (CERD) ha puesto sobre la mesa "las preocupantes informaciones recibidas acerca de los controles de identificación o redadas policiales, basados en perfiles étnicos y raciales, realizados en lugares públicos y barrios donde hay una alta concentración de extranjeros con la finalidad de detener a aquellos que se encuentran en situación irregular en el Estado parte (arts. 2,5 y 7)"(2011:3). Pero ya en el año 2006 la Comisión Europea sobre el Racismo y la Intolerancia (ECRI) denunciaba que los miembros de las minorías étnicas, especialmente marroquíes, sudamericanos y subsa- harianos, eran objeto de constantes e innumerables paradas, requerimientos de identificación y cacheos por parte de las fuerzas de seguridad.

Estos controles sistemáticos que realizan las fuerzas y cuerpos de seguridad en vías y espacios públicos son el primer paso del "ciclo de privación de libertad" que viven los migrantes "sin papeles" en España. El ciclo continúa con la conducción a comisaría de los migrantes que no puedan acreditar su estancia regular en el territorio y acaba con el internamiento en un CIE (Martínez EscamillaSánchez Tomás, 2011: 8). La actuación de la policía en las distintas fases de este ciclo es ilegal y quiebra derechos fundamentales de las personas migrantes. En primer lugar, y aquí seguimos a Martínez Escamilla y a Sánchez Tomás, la policía infringe la legalidad vigente cuando realiza una detención cautelar tras trasladar a una dependencia policial al migrante que en un control de identificación en la vía pública se identifica correctamente -con su pasaporte o mediante su cédula de inscripción consular- pero no acredita que se halla legalmente en España. El traslado a la comisaría y la posterior detención es ilegal por no tener cobertura legal, no la contempla ni la LOEx ni la LO 1/1992, de 21 de febrero, sobre Protección de la Seguridad Ciudadana, aunque está regulada bajo un redactado altamente confuso en la Circular 1/2010, de 25 de enero, de la Comisaría General de Extranjería y Fronteras. Así también lo entiende el Defensor del Pueblo en su Informe 2010, para quien "el traslado a comisaría sólo puede producirse por falta de la documentación que acredite su identidad y no de la que acredite la legalidad de la estancia". En segundo lugar, las fuerzas del orden españolas actúan ilegalmente cuando realizan controles sistemáticos de identificación a personas por sus rasgos étnicos o racionales. Esta práctica policial quiebra el principio de no discriminación del art. 26 del Pacto Internacional de Derechos Civiles y Políticos y del art. 21 de la Carta de los Derechos Fundamentales de la Unión Europea y el derecho a la igualdad y a la no discriminación recogido en el art.

${ }^{22}$ Directiva 2001/51/CE del Consejo, de 28 de junio de 2001, por la que se completan las disposiciones del artículo 26 del Convenio de aplicación del Acuerdo de Schengen de 14 de junio de 1985.

${ }_{23}^{23}$ Directiva 2004/82/CE del Consejo, de 29 de abril de 2004, sobre la obligación de los transportistas de comunicar los datos de las personas transportadas. 
$14 \mathrm{CE}$. Y lo hace por dos razones básicas: en primer lugar porque la selección étnica que realiza la policía en los controles de identificación convierten al "fenotipo" en criterio determinante para realizar estos controles, hecho que lesiona la dignidad de toda persona, $y$, en segundo lugar, por las consecuencias negativas que tales prácticas policiales producen en las personas migrantes, las cuales afectan seriamente su integración en la comunidad de residencia y fortalecer el estereotipo que relaciona minorías étnicas e inmigración con criminalidad, hecho que a su vez alimenta discursos xenófobos y racistas. Tales consecuencias negativas no guardan proporción con la supuesta efectividad de tales medidas de control y el valor del fin legalmente perseguido, a pesar de lo que diga el Tribunal Constitucional en su sentencia 13/200124(Martínez Escamilla y Sánchez Tomás, 2011: 18-23).

Los controles policiales por el perfil étnico influyen de forma muy negativa en la persona afectada pero también en el resto de los ciudadanos. Transmite una imagen distorsionada sobre su persona, lo asocia con delincuencia y criminalidad, y dificulta su integración en la comunidad al crearle miedo e inseguridad en su quehacer diario en los espacios públicos. El subsistema de coacción crea un estado de inseguridad y desconfianza sobre la persona migrante, poniendo de manifiesto, una vez más, su condición de semipersona. Esta condición se ve rebajada aún más en la privación de libertad que sufren las personas migrantes en los procedimientos de expulsión.

\subsection{De semipersonas a no-personas: la priva- ción de libertad en centros de internamiento}

Durante el procedimiento de expulsión la policía puede solicitar el internamiento del migrante en un CIE. En estas cárceles administrativas pueden ser internados los migrantes que tratan de entrar de forma irregular en el territorio, los que están a la espera de ser expulsados, ya sea por estar en situación ad- ministrativa irregular, porque han visto denegada su solicitud de asilo, o por estar cumpliendo condena y la administración penitenciaria decide la expulsión una vez han cumplido una parte de su condena, o los que son rechazados en las fronteras por las fuerzas de seguridad. No hay ciudad importante o puesto fronterizo europeo que no tenga una cárcel para privar de libertad a extranjeros indocumentados.

En España, los CIE fueron introducidos por primera vez en la ley de extranjería de 1985 . Hoy están contemplados como una medida cautelar que puede durar hasta un máximo de 60 días para asegurar la expulsión (art. 61.1e). Son definidos por legislador como "establecimientos públicos de carácter no penitenciario" donde son privados de su libertad ambulatoria con fines únicamente preventivos y cautelares migrantes indocumentados que están a la espera de ser expulsados (art.62.1.bis LOEx) ${ }^{25}$ Con la creación de estos centros administrativos de detención los países europeos han abierto la puerta a la formación de un nuevo subsistema carcelario específico para personas migrantes gestionado y bajo el control de la policía. La Directiva de la "vergüenza" permite que el internamiento pueda ser decidido únicamente por la policía (art.15.2) cuando, hasta ahora, siempre tenía que ser una autoridad jurisdiccional la que permitiera la privación de libertad por más de 72 horas.

En este nuevo sistema carcelario la privación de libertad ya no se produce por la imposición de una pena como consecuencia de la comisión de un delito, sino porque el migrante no cumple con unos requisitos administrativos. De este modo, el subsistema normativo del Estado expulsor quiebra el binomio culpable-inocente, calificado por la doctrina como una de las razones jurídicas básicas del Estado de derecho (Ferrajoli,1995: 368).

Ante esto y a la luz del art. 17 de la CE se puede cuestionar la legitimidad de la limitación de la libertad personal sobre la base de un presupuesto no penal o en ausencia de un hecho delictivo. Es verdad como sostiene el Tribunal Constitucional que la comisión

\footnotetext{
${ }^{24}$ La doctrina recogida en esta sentencia debe ser revisada en función de lo que se dice en el Dictamen del Comité de Derechos Humanos de Naciones Unidas de 17 de agosto de 2009 sobre el caso analizado en ella (Comunicación núm. 1493/2006).

${ }^{25}$ Para un análisis de los datos de las personas migrantes internadas en CIE en España, Grecia, Italia y Portugal en el período 2000-2009 ver Silveira (2011).
} 
de un hecho delictivo no es el único título que permite restringir la libertad. Mas la "excepcionalidad de la restricción o privación exige una proporcionalidad entre el derecho a la libertad y la restricción de esta libertad, de modo que se excluyan -aun previstas en la ley-restricciones de libertad, que no siendo razonables, rompan el equilibrio entre el derecho y su limitación" (STC 178/1985, de 19 de diciembre). El internamiento del extranjero "debe regirse por el principio de excepcionalidad, sin menoscabo de su configuración como medida cautelar" (STC 41/1982, de 2 de julio). El carácter excepcional del internamiento exige que el Juez aplique el criterio hermenéutico del favor libertatis, lo que supone que la libertad debe ser respetada salvo que se estime indispensable la pérdida de libertad del extranjero por razones de cautela o de prevención, que habrán de ser valoradas por el órgano judicial. Para el Tribunal Constitucional el carácter excepcional del internamiento estaba recogido en el art. 26.2 de la derogada Ley 7/1985, que aun cuando utilizaba el término "imprescindible" sólo respecto a la duración, implícitamente parecía que daba a entender que había de ser también imprescindible la propia pérdida de libertad, de modo que no era la substanciación del expediente de expulsión sino las propias circunstancias del caso -razones de seguridad, orden público, etc.- las que debían justificar el mantenimiento de la pérdida de libertad, siendo el Juez guardián natural de la libertad individual, el que debe controlar garantizar esas razones (STC 115/1987, de 7 de julio).

La libertad del extranjero, transcurridas las setenta y dos horas de detención, se encuentra a disposición judicial, hasta que el juez decida su puesta en libertad o hasta que la autoridad administrativa solicite del órgano judicial la entrega del detenido para proceder a su efectiva expulsión (STC 115/1987, de 7 de julio). El juez tiene que adoptar su decisión sobre la autorización del internamiento del extranjero pendiente de expulsión mediante resolución judicial motivada (STC 41/1982, de 2 de julio) y teniendo en cuenta principalmente las circunstancias concernientes a la causa de expulsión invocada, la situación legal y personal del extranjero, la mayor o menor probabilidad de huida o cualquier otra situación que el juez estime relevante. El juez de instrucción que autoriza el internamiento tiene que estar constantemente informado de las incidencias que se puedan presentar durante el mismo. Sin embargo, durante el transcurso del expediente de expulsión y del internamiento el migrante se encuentra muchas veces indefenso, sobre todo si el juez que gestiona su expediente se preocupa poco por su situación personal, pero especialmente cuando el juez que dicta la orden de internamiento no está en la misma ciudad o provincia que el CIE donde será internado el extranjero.

El cuestionamiento de que a una persona se le prive de libertad por no tener los permisos requeridos y como una medida cautelar para aplicar una sanción tiene relevancia también porque en un número importante de las expulsiones se interna a personas que luego deberán ser puestas en libertad. Esto sucede cuando la policía no puede ejecutar la expulsión como consecuencia de que no puede determinar la procedencia del inmigrante, no hay un convenio de readmisión con el país de origen del migrante o porque no dispone de fondos económicos para cubrir la ejecución de todas ellas.

Esto lleva a que miles de migrantes sean privados de libertad cada año en algún CIE para después volver a ser puestos en libertad. En España, entre el año 2001 y el 2005, se encontraron en esta situación alrededor de 122.000 extranjeros. ${ }^{26} \mathrm{Si}$ pasamos a ver datos de otros países mediterráneos encontramos que, por ejemplo, Grecia en seis años, sólo ejecuto 101.107 expulsiones (un 56,72\%) de los 178.253 expedientes abiertos, y dejó sin ejecutar 77.146 (un 43,28\%). Algo similar ocurrió en Portugal, de 21.064 expedientes incoados en 10 años, sólo llegó a ejecutar 6173 (un 29,3\%), dejando sin aplicar la mayoría de ellos, un $70.7 \%$. Esta diferencia entre el número de internados y expulsados plantea claramente un problema de eficacia de la ley de extranjería. El extranjero indocumentado se puede ver privado de libertad en una cárcel administrativa, en España por 30, 40 o 60 días, con el fin de ser expulsado para

${ }^{26}$ En el año 2009 en el conjunto de CIE españoles fueron internados 16.590 inmigrantes en proceso de expulsión administrativa, pero sólo fueron expulsados 8.935, el resto fue dejado en libertad; y en el año 2010 en el CIE Zona Franca de Barcelona fueron internados 1742 inmigrantes de los cuales fueron expulsados 1.118, y los otros 561 fueron puestos en libertad. 
luego ser puesto en libertad. Ante esta práctica hay que insistir en que todo extranjero internado debe ser puesto en libertad inmediatamente nada más tener conocimiento la administración si no lo va a poder expulsar en el tiempo requerido por el juez para el internamiento. Desde el momento en que la expulsión no se puede llevar a cabo debe acabar el internamiento, tal y como se establece en las sentencias del Tribunal Europeo de Derechos Humanos (Chahal v. UK de 15 de noviembre de 1996, Samy v. Netherlands de 1 de junio de 2002 y Saadi v. UK de 29 de enero de 2008).

Los que no pueden ser expulsados son dejados en libertad. Mas, como tienen una orden de expulsión no aplicada y el migrante en el fondo no debería estar en el territorio, la legislación hace que continúe sufriendo los efectos de su "irregularidad". Por ejemplo, la disposición adicional cuarta de la LOEx establece que las administraciones no tramiten las solicitudes que pueda hacer ante ellas en relación con procedimientos regulados en la misma ley. Formalmente el legislador no le permite iniciar los trámites que le permitirían precisamente escapar de la irregularidad. La ley lo excluye legalmente del ordenamiento jurídico y pasa a una situación de "alegalidad administrativa". Es un extranjero expulsable en potencia y, por tanto, no tiene derecho a tener derechos. Es tratado como una no-persona. El ordenamiento jurídico lo expulsa de su interior y pasa a ocuparse de él sólo para sacarlo de la alegalidad, "sancionar 'legalmente' su no-existencia y expulsarlo" (Dal Lago, 2000: 141-142).

Otro de los graves problemas que encierran los procedimientos administrativos de internamiento y expulsión es la deplorable situación en la que se encuentran la mayoría de los CIE y la constante quiebra de derechos y garantías de los migrantes internados en ellos. Son también innumerables las asociaciones de la sociedad civil que denuncian esta situación de degrado y piden el cierre de estos centros. En concreto, la Asociación Española para el Derecho Internacional de los Derechos Humanos
(AEDIDH) denuncia que en los CIE se discrimina a los migrantes porque no se respetan en particular los derechos a la salud pública, a la asistencia médi$\mathrm{ca}^{27}$ a la seguridad social y a los servicios sociales. Derechos que disponen los presos de las cárceles. Este trato discriminatorio se hace aún más grave si se tiene en cuenta también las condiciones inhumanas del internamiento, los frecuentes malos tratos y abusos que se producen en ellos, la escasa o inexistente defensa jurídica y las dificultades que tienen las personas internadas para entrar en contacto con sus familiares. Todo esto supone para la AEDIDH una quiebra de los artículos 5 y 6 de la Convención Internacional sobre la Eliminación de todas las Formas de Discriminación Racial (CIEDR) y del derecho a la libertad y a la seguridad personales del art. 3 de la Declaración Universal de Derechos Humanos y el art. 9 del Pacto Internacional de Derechos Civiles y Políticos $(2011,13) .{ }^{28} \mathrm{~A}$ raíz de este informe el Grupo Parlamentario de Esquerra Republicana-Izquierda Unida-Iniciativa per Catalunya Verds de las Cortes Españolas presentó en el Congreso una Proposición no de ley sobre el cierre de los centros de internamiento para extranjeros en la IX legislatura. ${ }^{29}$

Este tipo de propuestas deben vencer una oposición muy fuerte entre las fuerzas políticas del estado. Estas cárceles administrativas no sólo desempeñan un papel central en el funcionamiento de los Estados expulsores sino que también juegan una importante función simbólica ante la opinión pública. Hacen visibles las nuevas fronteras interiores del estado, mostrando a los ciudadanos quiénes no forman parte de ella y los que podrán ser expulsados -excluidos- de la comunidad si no cumplen con las exigencias establecidas por el orden público.

Desde el punto de vista de los derechos humanos los procedimientos de expulsión y los CIE representan el último eslabón de un proceso de despersonalización, en el sentido de no reconocimiento y de pérdida gradual de los derechos de la persona, al que se ve sometido el inmigrante "sin papeles" en la sociedad europea. En los CIE ya no se puede hablar

${ }^{27}$ Comienzan a producirse pronunciamientos judiciales sobre las deplorables situaciones de los CIE. Por ejemplo, ver el Auto del Juzgado de Instrucción n. 6 del 21 de diciembre de 2011 de Madrid sobre el CIE de Aluche.

${ }^{28}$ Ver también los Informes de Migreurop (2011) y CEAR (2009).

${ }^{29}$ Ver Boletín Oficial Cortes Generales, 11 de marzo de 2011, Serie D, Núm. 539. 
del migrante como semipersona sino del migrante como no-persona, donde es privado de libertad en condiciones inhumanas y con escasas posibilidades de defensa y tutela judicial.

\section{EL MIGRANTE COMO DESAFÍO PARA EL ESTADO DE DERECHO Y LA DEMOCRACIA}

La política de clausura de fronteras y la conversión de los Estados europeos en máquinas de detención, privación de libertad y expulsión de personas migrantes están socavando los principios básicos del Estado de derecho y de la convivencia social. El inmigrante no es tratado como un sujeto con derechos, sino como una semipersona o una no-persona. La mayoría de los inmigrantes en situación administrativa regular viven como metecos, con escasas posibilidades de intervenir en la esfera pública. Y los inmigrantes "sin papeles" deben hacer frente a las medidas de control y sanción.

En los procesos de despersonalización llevados a cabo por la biopolítica sobre los migrantes, fundamentada en el binomio dejar entrar-residir o expulsar, se hace visible el nuevo poder disciplinario-regulador que configura los nuevos espacios y senderos por donde transcurre la vida en la sociedad contemporánea (Mendiola, 2010: 54). La biopolítica sobre los migrantes es un claro ejemplo de cómo el poder soberano del Estado nación, redefinido en un marco geográfico supraestatal, tiene el encargo de gestionar la vida de miles de personas que acceden a su territorio, si los incluye o excluye de sus políticas de gobierno. Para ello deberá implementar mecanismos de regulación-gestión y control-sanción.

En este marco, los centros de internamiento para extranjeros se han convertido en un instrumento ordinario de intervención de los Estados en las políticas de extranjería. Forman parte del "derecho penal especial o administrativo" que el legislador ha venido configurando para disponer de instrumentos de control y represión sobre los migrantes. En este subsistema administrativo especial se establecen sanciones que son similares, en su esencia, a las penas y se quiebran derechos y libertades fundamentales de las personas.

La existencia de los centros de internamiento y retención constituye un grave atentado contra los derechos de las personas y pone en cuestión el mismo Estado de derecho. En el interior de éste se ha formado un subsistema penal administrativo, específico para personas extranjeras, que quiebra principios constitucionales básicos. Este subsistema pone de manifiesto que lo que debería ser una excepción, esto es, la detención y el internamiento del extranjero con normas hechas a medida y aplicables bajo circunstancias excepcionales, se ha convertido en una regla en el Estado democrático de derecho. Con la normalización de la excepción ésta ha pasado a formar parte de la razón jurídica, propia del Estado de derecho, cuando antes su espacio de actuación se situaba bajo la razón de estado. ${ }^{30}$

A diferencia de lo que sucedía en el pasado, donde el estado de excepción anulaba la ley, ahora la excepción se ha convertido en una forma de gobierno y ha pasado a integrar la propia estructura del Estado. La excepción regulada y normalizada no necesita anular a la ley, sino que más bien hace un uso ordinario de ella. En el Estado democrático de derecho una parte de la razón de estado, no toda, se ha integrado y se ha convertido en un subsistema de la razón jurídica con el fin de gobernar el fenómeno inmigratorio.

La paradoja de todo esto está en que en el ordenamiento jurídico español, pero también podemos hacer extensiva esta afirmación a otros países europeos, la contaminación de la razón jurídica por la razón de estado y el proceso de despersonalización de la persona migrante tienen su fundamento en la Constitución y en esa triada de derechos y libertades que la doctrina y la jurisprudencia elaboran sobre los migrantes. Es la Constitución la que abre la puerta a que los migrantes pasen a estar regulados por un subsistema legal-administrativo con reglas más restrictivas, muchas de ellas discriminatorias y abusivas, que las que rigen para los ciudadanos españoles y europeos. Esta legislación no tiene visos de cambiar, sino que, al contrario, ha sido reafirmada con la aprobación de la Directiva de la expulsión. La

\footnotetext{
${ }^{30}$ Sobre la primacía de la razón de Estado sobre la razón jurídica y la incompatibilidad entre ellas en el Estado de derecho ver Ferrajoli (1995: 808-816).
} 
razón de estado no sólo se ha incardinado en la razón jurídica sino que además pasa a estar legitimada por el principio democrático.

Si volvemos la vista hacia atrás encontramos que en el marco de los procesos de modernización de los siglos XIX y XX la razón jurídica del Estado de derecho se ha ido transformado en una razón "securitaria", con el fin de que los gobiernos puedan implantar medidas de control, vigilancia y represión sobre el conjunto de las poblaciones (Foucault, 1992: 24). Así, el Estado expulsor muestra el resurgir de un Leviatán en permanente tensión con los principios del Estado de derecho. Este nace de una violencia impuesta y su supervivencia como soberano pasa por el ejercicio de una "violencia administrada". El derecho moderno tiene una cara bifronte. La violencia, como señala Benjamín, está presente tanto en el momento de creación del derecho como en el de su conservación (1971: 172). La conversión de las personas migrantes en "no-personas" pone de manifiesto hasta qué punto la violencia es un fenómeno inmanente a las instituciones jurídico-políticas modernas.

La relación de ocultación y de mímesis entre derecho y violencia en la sociedad moderna es, como señala Baratta, uno de los problemas "congénitos de la modernidad" (2000: 197). La sociedad moderna se autoconstituye y regula sobre la tranquilizadora creencia de que orden social se podrá construir si el Leviatán logra eliminar las violencias existentes en el cuerpo social para encarnarlas en el derecho, el único legitimado para ejercitarla. El orden se fundamenta en la "certeza" de que la soberanía y el derecho son las únicas respuestas racionales y posibles a la violencia difusa en la sociedad. La violencia del soberano, regulada por la ley -la denominada violencia legal- se presenta como el único remedio, el único antídoto eficaz contra la violencia (Resta,1995:37). Sin embargo, este planteamiento deja la puerta abierta al peligro de que el instrumento de regulación, el derecho, acabe por convertirse tam- bién en una mímesis de la violencia que pretende controlar.

En las últimas décadas el Estado contemporáneo ha ido adquiriendo nuevos "contornos bélicos" que se manifiestan en un neopunitivismo, la deshumanización-militarización del sistema penal, el reconocimiento y la aceptación de la tortura, el control de los flujos migratorios, la represión de los migrantes "sin papeles", el incremento y el uso de las sanción administrativa como una nueva pena, la extensión del miedo y la construcción de emergencias urbanas en las grandes ciudades (Fernández-SilveiraRodríguez-Rivera, 2010). Todo esto hace que en el Estado "securitario" sea cada vez más difícil marcar la frontera entre la violencia lícita (legal) y la ilícita (ilegal).

Detrás de este Estado securitario con sus contornos bélicos hay un imaginario social que interviene e influye en la reproducción y el funcionamiento del orden social. Por ello, a la hora de analizar el Estado securitario no es posible ignorar el papel que juega lo que Castoriadis denomina la "clausura de sentido" o Derrida el "exterior constitutivo" en la comunidad. ${ }^{31}$

\subsection{La "clausura de sentido" y el "exterior constitutivo"}

Todo grupo humano, señala Castoriadis, busca mantener su cohesión en el espacio y en el tiempo, algo que se consigue también mediante la diferenciación de los foráneos. Este proceso de diferenciación y, al mismo tiempo, de exclusión de lo exterior se produciría por el hecho de que todo grupo social necesitaría crear su propio mundo de sentido -sus propias "significaciones sociales imaginarias ${ }^{32}$ para mantenerse unido como comunidad. Para el filósofo griego la práctica totalidad de las sociedades conocidas se han instituido mediante una clausura de sentido, en el sentido de que toda sociedad es portadora de un significado que la cierra, la clausu-

\footnotetext{
${ }^{31}$ Para un análisis de la literatura de la biopolítica sobre las migraciones, la seguridad y los confines territoriales en el contexto de la globalización ver Campesi (2012).

32 Significaciones sociales imaginarias pueden ser, por ejemplo, espíritus. dioses, polis, ciudadano, nación, estado dinero, virtud, hombre, mujer. Castoradis las llama "imaginarias" porque no corresponden a elementos "racionales" o "reales", sino que están dadas por creación; y las llama "sociales" porque sólo existen estando instituidas y siendo objeto de participación de un ente colectivo impersonal y anónimo (Castoriadis, 1994: 68).
} 
ra, ante el mundo exterior, fenómeno que al mismo tiempo determina que la sociedad sea más cerrada o más abierta en función de cuáles sean los significados que intervienen en este proceso de clausura (2000: 184).

En la "clausura del sentido" los territorios, las fronteras, los foráneos adquieren importancia en función de los sentidos específicos que los miembros y las instituciones de una sociedad específica les atribuyen. Así, un extranjero es tal "porque las significaciones de las que está imbuido son extranjeras, lo que quiere decir que necesariamente son siempre extrañas". Estas significaciones se van produciendo a lo largo de proceso de socialización del individuo desde un sentido inicial coextensivo a su propia esfera psíquica privada (sentido "monádico") a un sentido social común. El sentido de la vida del individuo va cambiando a medida que va pasando por un proceso paulatino de identificación con ámbitos cada vez más amplios de las significaciones sociales existentes en el mundo instituido: desde la familia, la parentela, el grupo de edad, pasando por el clan, la clase social, hasta llegar a la nación y la etnia. Esto quiere decir, que "todos los polos de identificación del individuo corresponden al mundo instituido de las significaciones sociales, en el que evidentemente ocupan un lugar central las significaciones referidas a las diferentes entidades colectivas instituidas de las que el individuo es un miembro o un elemento" (2000: 185). Cuanto más cerrada es una sociedad más fuerte es la identificación de sus miembros con ella. El racismo puede asumir varias formas según como sea construida la relación con el "otro". Además de la separación o el aislamiento puede establecer también una relación de rechazo y destrucción del "otro" o bien de dominación y asimilación. Lo que es común a todas estas formas es la pretensión de establecer un privilegio, de realizar una exclusión, para dar ventajas a unos y perjudicar a otros.

Pues bien, en este mundo de significados instituidos estarían también las raíces del rechazo, temor y odio hacia el "otro". La búsqueda de certezas últimas por parte de la psique origina muchas veces procesos de identificación fuertes con las creencias de unos determinados colectivos, hecho que puede dar lugar también a comportamientos de desprecio y beligerantes hacia los que no comparten esas creencias o que forman parte de otro grupo. En el origen de estos comportamientos hay, para Castoriadis, un rechazo de la psique del sujeto a aceptar lo que para ella es extraño. El odio al otro hunde sus raíces en el la cuasi-exigencia de la clausura del sentido. El racismo, así es "la aparente incapacidad del sujeto de constituirse en sí sin excluir al otro $-y$ de la aparente incapacidad de excluir al otro sin desvalorizarlo y, finalmente, odiarlo" (Castoriadis, 1993: 26). ${ }^{33}$ En este sentido, la xenofobia y el racismo están directamente vinculados con el modo cómo se desarrolla el proceso de socialización-identificación del individuo.

Llegados a este punto la pregunta que debemos hacernos es por qué los seres humanos no pueden considerar a los "otros" como lo que son: simple alteridad, esto es: una persona con otra forma de vida, con otras costumbres, lengua, religión. Dicho con otras palabras: por qué la diferenciación de lo extraño, o el acto de reafirmación del mundo propio -la "clausura de sentido"- va acompañado de la desconfianza, del rechazo, el desprecio hasta llegar a la discriminación, la exclusión e incluso el confinamiento y la violencia sobre el "otro". Castoriadis considera que una respuesta posible a estos fenómenos estaría relacionada con la disolución que se produce en la sociedad moderna de casi todos los grupos colectivos -familia, clases sociales- que hacen de intermediarios y de referentes sociales en las relaciones entre los individuos. La pérdida de estos referentes y de los vínculos sociales provocaría que aquéllos acaben por identificarse con otras entidades, como la "religión", la "nación", la "raza", algo que, en suma, acabaría por exacerbar aún más las diferencias respecto a todos aquellos que no formen parte de esas entidades (2000: 192). Foucault, por

\footnotetext{
${ }^{33}$ Castoriadis intenta mostrar que el odio tiene dos fuentes que se refuerzan entre sí: una raíz psíquica, por la tendencia de la psique a rechazar (y así, a odiar) lo que no es ella misma; y una raíz social, derivada de la necesidad de las significaciones imaginarias existentes en una sociedad de cerrarse ante las significaciones existentes en el mundo exterior.
} 
su parte, contestaría diciendo que ello se debe también a que la ideología racista logró insertándose en los mecanismos de poder y de gobierno del Estado moderno (1992: 263-264). El racismo fue utilizado por el biopoder para diferenciar a unos grupos de otros. El discurso sobre las razas permite fragmentar el campo biológico sobre el que actúa el biopoder, y aporta el discurso legitimador para que éste garantice la vida de unos a costa de la exclusión, discriminación, explotación e, incluso, el sufrimiento y la muerte de otros. ${ }^{34}$

Más allá de estas respuestas, lo que sí podemos afirmar es que detrás de las actuales legislaciones sobre las personas migrantes y de la conversión de los Estados europeos en Estados expulsores, hay organizaciones sociales y políticas xenófobas y de ideología racista. El apoyo que les da una parte de la opinión pública les ha permitido acceder a los órganos de gobierno nacionales, regionales y locales o influir de forma decisiva en sus políticas.

El ideario racista de estos grupos se fundamenta en un nuevo diferencialismo cultural en el que la etnia o el grupo autóctono ocupa el lugar que antes ocupaba la raza. El reclamo de unas pretendidas diferencias biológicas y genéticas ha dado paso a la defensa de las diferencias culturales entre los grupos étnicos con el fin de evitar que el mestizaje entre autóctonos y foráneos pueda "desnaturalizar" o poner en peligro la identidad y la forma de vida del grupo que acoge al migrante. El nuevo racismo contra los inmigrantes interpreta la pérdida de los vínculos sociales y la anomia existente en las periferias urbanas reclamando una presunta comunidad originaria cuyas virtudes habrían sido transformadas, supuestamente, por aquéllos que no forman parte de ella. En este sentido, la identidad comunitaria, en la medida que apela a una unidad $\mathrm{u}$ homogeneización de la comunidad, favorece la estigmatización de los que no comparten los valores de la comunidad o no forman parte de ella: los otros" (Wieviorka, 1992). Esta nueva ideología racista necesita que el "otro", el foráneo sea caracterizado y diferenciado ya no a través del fenotipo sino mediante otros elementos y rasgos como pueden ser la lengua, la cultura, la moral, la religión, las costumbres, etc.

Este nuevo racismo necesita identificar unos rasgos morales y culturales como propios de un determinado grupo y atribuirlos a cualquier individuo perteneciente a ese grupo. Este proceso de estigmatización convierte a las personas migrantes no europeas en los "otros" por excelencia. La consecuencia principal de todo esto es la de poner en pie un nuevo racismo segregacionista. ${ }^{35}$ Esta ideología diferencialista es compartida también por partidos políticos nacionalistas y comunitaristas preocupados por la salvaguarda de las identidades, las tradiciones y la forma de vida de las poblaciones europeas. Para estos partidos, como la Liga del Norte de Italia, el Frente Nacional de Francia. el Partido Liberal de Austria o Plataforma por Cataluña en España, las personas migrantes constituyen los nuevos "enemigos" simbólicos de la patria. Sus discursos no hacen más que remarcar las diferencias entre los de aquí y los de fuera y fomentar, en consecuencia, las políticas de discriminación y de segregación. Pero sus verdaderas pretensiones no son tanto las de impedir un mestizaje entre grupos y culturas, sino sobre todo las de evitar que las personas migrantes -los "otros"puedan acceder a los bienes y servicios públicos que dispone el grupo autóctono.

El fenómeno de la "clausura del sentido" pone de manifiesto que la "pertenencia" a algún grupo humano viene determinada por el proceso de autoconstitución de la propia sociedad y por los significaciones sociales que la institución como un todo y las instituciones existentes en ésta se dan de sí mismas y, en consecuencia, de los "otros". La sociedad como un todo se suele autodefinir y autoconstituir, por lo general, mediante discursos de diferenciación

\footnotetext{
${ }^{34}$ La experiencia del nazismo lleva a Agamben a contraponer a la formulación de Foucault de la biopolítica como aquella que "hace vivir y deja morir", la de hacer sobrevivir. Para Agamben la aportación decisiva del biopoder contemporáneo es la "producción de una supervivencia modulable y virtualmente infinita" (2005: 162-163).

${ }^{35}$ El racismo puede asumir varias formas según como sea construida la relación con el "otro". Además de la separación o el aislamiento puede establecer también una relación de rechazo y destrucción del "otro" o bien de dominación y asimilación. Lo que es común a todas estas formas es la pretensión de establecer un privilegio, de realizar una exclusión, para dar ventajas a unos y perjudicar a otros.
} 
de lo externo, de aquello que no forma parte del mismo grupo o comunidad. La condición de miembro del grupo se suele determinar por exclusión o por diferenciación de aquellos que son concebidos como ajenos al mismo. En este sentido, podemos decir que todo grupo -toda comunidad- suele tener, dice Derrida (1977) un "exterior constitutivo" que interviene en el proceso de creación de la identidad del grupo y que, en última instancia, incluso lo hace posible como tal. Las barreras existentes entre los ciudadanos europeos y las personas migrantes se alimentan tanto de legislaciones e instituciones públicas, que remarcan los límites del territorio y de la ciudadanía -cupos de inmigración, leyes de extranjería, permisos de residencia, mecanismos de expulsión- como de unos discursos ideológicos y políticos, que transforman las diferencias entre ciudadanos y migrantes en una contraposición ontológica: es decir, entre mundos culturales radicalmente opuestos y que por ello, para algunos, no "deben" convivir en un mismo espacio. Hoy día el migrante extracomunitario, especialmente como consecuencia de las políticas de inmigración y extranjería aplicadas por los gobiernos, está desempeñando el papel de "exterior constitutivo" en el proceso de configuración de algo inexistente hasta ahora como es el "demos" -el pueblo- de la propia Unión Europea.

\subsection{La vida en común}

Las políticas de inmigración y de extranjería sacan a la luz la ambivalencia y las contradicciones de la cultura política democrática existente en España y el resto de los países europeos. Por un lado, se promueven manifestaciones contra el racismo y se castigan penalmente los actos racistas, pero, por otro, se establecen medidas restrictivas respecto a las personas migrantes, se reducen sus derechos, libertades y garantías, se establecen barreras legales y exámenes culturales para realizar, paradójicamente, una correcta integración y se persigue hasta su expulsión a los "sin papeles". A pesar de las denuncias de las organizaciones defensoras de los derechos humanos, el gobierno español y los europeos mantienen las políticas de inmigración realizadas hasta ahora, e incluso las endurecen, apoyados en una parte importante de la opinión pública que les da sostén.
Ante la extensión de la violencia institucional de los Estados expulsores y desde el punto de vista de los derechos de las personas y de la convivencia en una sociedad mínimamente democrática es necesario defender los principios del Estado de derecho e intentar evitar que se enquisten en sus instituciones mecanismos que quiebran derechos y libertades fundamentales. La convivencia bajo un Estado de derecho pasa por intentar garantizar derechos, libertades y garantías para todas las personas que se encuentran en el territorio, especialmente de aquellas que están en situaciones de extrema necesidad como son los desplazados, menores desamparados e inmigrantes indocumentados. La persona migrante debe ver respetados sus derechos y libertades fundamentales $y$, en el caso de que opte por su integración en la comunidad receptora, debe tener la posibilidad de participar y tomar parte en los asuntos de interés general en la esfera pública.

Esta lucha por los derechos, libertades y principios del Estado de derecho debe ir acompañada de un cambio radical en los discursos y en las políticas de inmigración y de extranjería de los gobiernos europeos. Las instituciones públicas no pueden actuar como instancias reproductoras del antagonismo autóctonos-foráneos (migrantes) sino que deberían hacer lo posible para desactivar este antagonismo. Con este fin deben trabajar también organizaciones sociales y políticas, proponiendo soluciones para aquellas circunstancias sociales, culturales, económicas y políticas que originan o que están detrás de las conductas xenófobas, discriminatorias y que, en consecuencia, no hacen más que incrementar el antagonismo y la violencia entre los de aquí y los de fuera. Hoy no cabe otra opción que la de construir entre todos la vida en común.

Por todo ello también se hace necesario que las instituciones públicas y los agentes sociales, como los partidos políticos, sindicatos y ONG reciban el impulso de prácticas sociales que busquen el reconocimiento mutuo entre ciudadanos y migrantes. Ante el nuevo panorama socio-político que está tejiendo la globalización neoliberal hay que intentar que la democracia se convierta en una "forma de vida". Entendemos que con el avance de la democracia y la multiplicación de los espacios sociales en los que las relaciones de poder pasen a estar abiertas a la participación y al control de los ciudadanos se abri- 
rían puertas que permitirían transformar y eliminar aquellos mecanismos institucionales y sociales que actúan como reproductores de desigualdades sociales, que fomentan la discriminación y la exclusión hacia los migrantes y que están detrás de la violencia institucional de los Estados expulsores.

\section{BIBLIOGRAFÍA}

AA.VV. (2008). Frontera Sur. Nuevas políticas de gestión y externalización del control de la inmigración en Europa, Barcelona: Virus.

ACHON, O. (2011) Importando miseria. La alternativa a la provisión de mano de obra agrícola. Madrid: La Catarata.

Agamben, G. (2005), Lo que queda de Auschwitz. El archivo y el testigo. Homo Sacer II, 1, Valencia: Pre-textos.

Agüelo Navarro, P. y Chueca Sancho, A.(2008) "Directiva de retorno. Directiva de expulsión (Nota crítica a vuelapluma desde los Derechos Humanos)", en Revista de Derecho Migratorio y Extranjería, n.18.

Agüelo Navarro, P. y Chueca Sancho, A.(2009), "La reforma de la Ley de Extranjería. Una crítica desde los Derechos Humanos", en Revista de Derecho Migratorio y Extranjería, n. 22.

Amnistía Internacional (2011), Parad el racismo, no a las personas. Perfiles raciales y control de la inmigración en España.

ASOCIACIÓN ESPAÑola paRA EL DERECHO INTERNACIONAL DE LOS DERECHOS HUMANOS (AEDIDH), (2011), Dictamen Los Centros de Internamiento de Extranjeros.

Balibar, E. (2003). Nosotros, ¿ciudadanos de Europa?, Madrid: Tecnos.

Baratta, A, (2000): "El Estado mestizo y la ciudadanía plural. Consideraciones sobre una teoría mundana de la alianza", en H.Silveira, Identidades culturales y democracia, Madrid: Trotta.

Benjamin, W. (1971), "Para la crítica de la violencia", en Id., Angelus Novus, Barcelona: Edhasa.

CAmpesi, G. (2011): Soggetto, disciplina, governo. Michel Foucault e le tecnologie politiche moderne, Milano: Mimesis.

(2012): "Migraciones, seguridad y confines en la teoría social contemporánea", en Crítica Penal y Poder, n.3 (revista electrónica) http://revistes.ub.edu/index.php/CriticaPenalPoder.

CAstoriadis, C. (1994): Los dominios del hombre: las encrucijadas del laberinto, Barcelona: Gedisa. (2000): Figuras de lo pensable, Madrid: Cátedra

CEAR, (2009): Situación de los Centros de Internamiento para Extranjeros en España.

COMité PARA LA ELIMINACiÓn DE LA DISCRIMINACiÓn RACIAL (CERD), (2011): Examen de los Informes presentados por los Estados partes de conformidad con el artículo 9 de la Convención (CERD/C/ESP/ $\mathrm{CO} / 18-20)$.

Chueca SAncho, A.G., (2010): "Un derecho migratorio europeo cada día más incompatible con el derecho internacional de los derechos humanos", en A.G. Chueca Sancho (dir.), Derechos Humanos, Inmigrantes en situación irregular y Unión Europea, Lex Nova, Madrid.

Dal Lago, A. (2000): "Personas y no-personas", en H. Silveira (ed.), Identidades comunitarias y democracia, Madrid: Trotta.

Defensor del Pueblo (2005), Informe sobre asistencia jurídica a los extranjeros en España, Madrid. (2011), ¿Menores o adultos? Procedimiento para la determinación de la edad.

Derrida, J. (1977): Posiciones, Valencia: Pre-textos.

Dirección General de Servicios Penitenciarios. (2011), Circular 1/2011, sobre estrangeria als centres penitenciaris de Catalunya.

Espósito, R. (2004), Bíos. Biopolitica e filosofia, Torino: Einaudi. 
Fernández, Silveira, Rodríguez, Rivera (eds.), (2010), Contornos bélicos del Estado securitario. Control de la vida y procesos de exclusión social, Barcelona: Anthropos.

FerRajoli, L. (1995): Derecho y Razón. Teoría del garantismo penal, Madrid: Trotta.

Foucault, M. (1992), Genealogía del racismo, Madrid: La Piqueta.

Gomez-Ferrer, R.J.; Ortega Carballo, C; RipollCarulla, S. (2010), Derechos fundamentales de los extranjeros en España, Valladolid: Lex Nova.

De Lucas J. (2008), "Politiques migratories, Estat de Dret $i$ Ciutadania" (mecanoscrito), ponencia presentada al seminario Desafiaments per als drets humans i l'Estat de dret. Control de les migracions a Europa, OSPDH-CCCB, mayo 2008.

Martinez Escamilla, M, SÁnchez Tomás, J.M. (2011), "Controles de identidad, detenciones y uso del perfil étnico en la persecución y castigo del inmigrante "sin papeles": ilegalidad e inconstitucionalidad de determinadas prácticas policiales", en http://www.inmigrapenal.com.

Mendiola, I. (2009), "La bio(tanato)política moderna y la producción de disponibilidad", en

Mendiola, I (ed.), Rastros y rostros de la biopolídica, Barcelona: Anthropos.

MIGREUROP (2010), Aux frontièresde l'Europe. Contrôles, enfermements, expulsions. Rapport 20092010.

(2011): CIE Derechos Humanos. Resumen ejecutivo. Informe sobre los centros de internamiento en España.

Ministerio DEl InTERIOR, (2008), Balance de la lucha contra la inmigración ilegal 2008. (2009), Balance de la lucha contra la inmigración ilegal 2009.

Moya Malapiedra, D. (2006). "La desigual representación política dels estrangers extracomunitaris: l'amplicació del dret de sufragi com a solució i com a problema", en Silveira-Cornelles-Juberias (eds.), Immigració i Ciutadanía. Reptes de la Catalunya del segle XXI, Barcelona: Fundació Pere Ardiaca.

Moya Malapiedra, D. (2010), "Regulación del derecho se sufragio de los extranjeros en España y los mecanismos alternativos de participación política", en Moya Malapiedra, D., Viñas Ferrer, A. (eds.), (2010): Sufragio y participación política de los extranjeros extracomunitarios en Europa, Barcelona: Fundació Pi y Sunyer.

OBSERVATORIO EUROPEO DE GERONTOINMIGRACIONES (OEG) (2011), “Gerontoinmigración y voto en España”, en Boletín OEG de Investigación, $\mathrm{n}^{\mathrm{o}} 1$.

PAvón Pérez, J.A. (2008): La propuesta de Directiva relativa al retorno de los nacionales de terceros países que se encuentren ilegalmente en la Unión Europea: ¿un difícil juego de prestidigitación camino de la armonización de procedimientos y normas comunes?, Revista de Derecho Migratorio y Extranjería, n. 19.

Resta, E. (1995), La certeza y la esperanza. Ensayo sobre el derecho y la violencia, Barcelona: Paidós.

Silveira Gorski, H.C., Rivera, I. (2009): La biopolítica contemporánea ante los flujos migratorios y el universe carcelario. Una reflexión sobre el regreso de los "campos" en Europa”, en I. Mendiola Gonzalo (ed.), Rastros y rostros de la biopolítica, Barcelona: Anthropos.

Silveira Gorski, H.C. (2010). "Estados expulsores y semipersonas", en Fernandez, Silveira, Rodriguez Rivera (eds.) Contornos bélicos del Estado securitario. Control de la vida y procesos de exclusión social, Barcelona: Anthropos.

Silveira Gorski, H.C.(2011). "Análisis de los datos de las personas extranjeras detenidas, internadas y expulsadas en España, Grecia, Italia y Portugal”, en Crítica Penal y Poder, n.1 (revista electrónica) http://revistes.ub.edu/index.php/CriticaPenalPoder.

Wieviorka, M. (1992): El espacio del racismo, Barcelona: Paidós. 